\title{
'Catching Glimpses of Disciplinary Understanding': Collaborative Teaching, Learning, and Inquiry (A Review of Teaching, Learning, and the Holocaust: An Integrative Approach)
}

We built the course, and they came.

Tinberg \& Weisberger, Teaching, Learning, and the Holocaust: An Integrative Approach

...not only did I learn a tremendous amount about the Shoah, I learned it through unlearning.

Richard, a student in the class, as quoted in Tinberg \& Weisberger, Teaching, Learning, and the Holocaust: An Integrative Approach

Howard Tinberg's and Ronald Weisberger's book Teaching, Learning, and the Holocaust: An Integrative Approach (2014) presents a great opportunity for discussing several critical issues that are important to all of us as classroom practitioners, curriculum planners, and scholars in the Scholarship of Teaching and Learning. Among the important issues raised in this book are the following:

- The question of disciplinary borders and the challenging issue of collaborative teaching across disciplinary borders;

- The question of empathy in teaching and learning, particularly in the context of teaching and learning about an issue as difficult as the Holocaust;

- The question of presentation, representation, and interpretation; of parallel sets of discourses that emanate from the assigned texts themselves, from the students who have been assigned these texts, and from the teachers who facilitated this conversation in the classroom;

- The question of teaching and learning as a journey, for some coming from a very well defined starting point, and for others, a journey that came "from somewhere else" (p. 10), and how this journey, wherever it originated, can nevertheless be a transformative experience in learning, unlearning, and relearning, both for students and teachers. 
These are all important and fascinating issues, and this brief review cannot hope to do justice to all of them. I have commented on the question of empathy elsewhere (see Chng, 2014), where I acknowledged that there may indeed be a limit to empathy, particularly when it comes to traumas like the Shoah experience. As teachers, however, our duty is to cultivate empathy in ourselves and in our students, even given the possibility of failure. Here, I will focus on the first issue which is, in my view, most relevant to classroom practitioners situated at all levels of teaching but perhaps particularly at the tertiary level: the question of disciplinarity, interdisciplinarity, and collaborative teaching across disciplinary borders.

Teaching, Learning, and the Holocaust documents a journey the authors jointly took from 2002, one coming from literature and the other from history, when they embarked on a co-teaching venture on a course that they titled "Remembering the Holocaust in Literature and History: An Honors Interdisciplinary Seminar.” The objectives of this course, as they planned it, are captured within their course description:

The Holocaust, or, as it has come to be known, the Shoah, is one of the most horrific events in all of world history. Even more than fifty years after the fact, the world continues to struggle with the enormity of this human catastrophe. Nevertheless, a body of writing-both historical and literaryexists that enables us to confront this key moment in world history. This course serves as an introduction to this work. Students gain an understanding of the historical facts, including circumstances leading up to the Holocaust itself and the event's critical aftermath. In addition, students reflect on the role of literature, principally through accounts of that time written by survivors and the children of survivors, in the struggle to represent an event that many have described as beyond the limits of language to capture (pp. 23-24; emphasis added).

By "students," the authors refer to young people in their early 20 s or older, from diverse ethnic backgrounds, mostly non-Jewish, attending Bristol Community College in Fall River, Massachusetts (US). Most of them had little or no knowledge of Jewish people, Judaism, or any deep understanding of the Holocaust other than the relatively superficial, such as having seen movies like Schindler's List. As with any student on any campus around the world who had little or no experience of interdisciplinary courses, these students approached this particular course with an expectation of disciplinary "neatness:" some thought it would be "a full-fledged survey of literature from the Shoah" while others expected "a straight history course" (p. 33). And the instructors played a role, especially in the early days of their collaboration, in contributing to this expectation of neatness, with one preferring a narrative mode to the other's lecture approach. The course design further reinforced the separateness of the two disciplinary perspectives, when students were required to attend to both the history and literary texts as if they were separate modes of discourse. Two courses were indeed pretending to be one (p. 5). We may ask, and some of us who have tried would probably have asked ourselves before, why it seems such a struggle to collaborate and teach across disciplines. Why is interdisciplinarity a challenging enterprise even for the best teachers among us?

I have attempted collaborative teaching across disciplinary domains twice in my teaching career, and I can attest to the logistical, pedagogical, and intellectual challenges 
of such a collaborative teaching project. Tinberg and Weisberger's admission that they both knew from the beginning that "collaboration makes so much sense" (p. 37) resonates well with me - that had been the primary driving force for me too (other than curiosity) when I embarked on such a project with two colleagues on two different occasions. I believe most academics know and can agree that there are limits to disciplinary inquiry, especially when inquiry is kept strictly within the confines of specific disciplines. A rigorous and fuller understanding of any subject requires the contributions from different fields, with each field adding a perspective to enable the richness in characterization of the subject. But this ideal is easy enough to state yet somewhat hard to achieve for most of us because disciplinary borders have proven to be some of the hardest borders to cross. Citing Messer-Davidow, Shumway, and Sylvan (1993, p. vii), Tinberg and Weisberger noted, and I cannot agree more, that we have been "disciplined by our disciplines" (p. 4).

A first difficulty in traversing disciplines is that what may be taken to be acceptable practices in one discipline can prove quite alien to another. Here, I have in mind the differences in what constitute the 'correct' methods, what is accepted as evidence, or even what counts as a good question in a field of inquiry. I have often heard colleagues arguing over such questions of validity, and individuals getting very upset by the perceived lack of understanding and acceptance of other disciplinary ways of thinking and knowing. In the context of Tinberg and Weisberger's teaching of the Shoah, the separation of disciplines was framed in terms of Lee Shulman's statement about domain specificity:

... how we teach and how our students learn are questions necessarily tied to what comprises our course content. That content may include more than purely the facts (the formulas, key events, and concepts) of a subject but also the methods and ways of thinking characteristic of particular disciplines, what we refer to below as rhetorical processes. Furthermore, an assessment of teaching and learning should itself be grounded in those very research methodologies afforded by the disciplines ( $p .25)$.

As stated above, being tied to content, methods, "ways of thinking characteristic of particular disciplines," and the rhetorical practices peculiar to each discipline-these domain specificities conspire to stop us from venturing out into co-teaching beyond our immediate domains, even when we instinctively know that when we collaborate and collaborate well, we bring many advantages to our students' learning. And significantly, collaborative teaching also educates and contributes to our own growth as teachers. Though their collaboration has not necessarily yielded a satisfactory answer for all their questions, it is clear from reading the documentation of their journey that these two authors and teachers have nevertheless achieved a comfort level in co-constructing a hybrid syllabus where literature is interwoven with history.

A second and related challenge of interdisciplinary collaboration is the limits presented by our own understanding, our own inability to see beyond the ways of our own discipline and the way we approach the teaching of a particular subject. I have certainly encountered many colleagues who-when approached to work outside their comfort zone, whether to adopt a teaching activity that she hasn't used before or a different way of engaging students-would immediately say "No, that would not work for my subject matter/my class/my students." In my view, Shulman's position that teaching and learning are domain-specific is true for the most parts, but I do believe that there are also over- 
arching principles of pedagogy and student engagement that translate well across different disciplines, particularly at a macro level. For example, the literature professor's preference for narrative and discussion over the history professor's preferred lecture mode as a dominant classroom practice does not mean that the former has no use for lectures or the latter could not usefully experiment with a more discussion-based pedagogy. Pulling various perspectives together on one platform, whether it is to deploy a hybrid reading list (in this case, history and literary texts) or to experiment with different classroom activities (from reflective journals to formal essays), if well scaffolded, can only serve our students well as these can add a broader and more holistic understanding of a subject. Tinberg and Weisberger's attempt to go beyond the history of the Shoah and infuse narrative storytelling into the historical dimension serves to give voice to a historical event, and also anchors these voices (of survivors and witnesses of the Shoah) in specific historical moments.

Finally, there is the sacred idea of the classroom as a private space, a space that is "ours to do with as we wish" (p. 106) when teaching and learning should be made more public, so that we receive objective critique and validation of our art. Shulman puts it this way:

For a scholarship of teaching, we need scholarship that makes our work public and thus susceptible to critique. It then becomes community property, available for others to build upon (Shulman, 1999; emphasis added).

Tinberg and Weisberger rightly point out that we need to get over our own discomfort of having our teaching scrutinized by our peers and that we should develop our confidence in teaching in front of other colleagues (p. 106). I agree that these are important. However, the emphasis I wish to put on Shulman's statement is expressed in the second part above: that of teaching as "community property" and the subsequent build-up from the base that is made available. I find the idea of teaching as "community property" particularly interesting, as this manner of viewing teaching enables what we and others do to serve as a base or foundation for further work. I have witnessed too much reinventing of the wheel in teaching as each person works to craft a course alone and often from scratch. In the same way that we have preached the benefits of peer learning to our students when we get them to work in groups, we teachers need to collaborate more with our own peers in teaching, much in the same way research collaboration is the norm in many disciplines. Tinberg and Weisberger's collaborative teaching project is therefore a good example of how we can start to work together and broaden our own pedagogical horizon in the process.

In sum, what I have gathered from reading Teaching, Learning, and the Holocaust: An Integrative Approach about the essentials for success in collaboration are the following:

1. To minimize, if we cannot fully eradicate, disciplinary boundaries, particularly when we say we wish to teach an interdisciplinary course. In Tinberg and Weisberger's case, the binaries presented in history/literature, fact/fiction, cognitive/ affective, lecture/discussion, witnessing/imagination, objectivity/trauma came to be understood not as mutually exclusive choices that ignore other perspectives but as two perspectives that can be usefully embraced and welded to the benefit 
of both students and teachers. We need to resist and escape being confined within our own disciplines, take the first step to move beyond disciplinary constraints, and engage in cross-disciplinary conversations.

2. To accept all of us as "authors in this [collaborative] model" (p. 39), co-constructing multiple perspectives to add to a rich tapestry that enables us to more fully understand, in this case, the traumatic history of the Shoah as testified not just in history books but also in literary texts. What was taken to be 'facts' in one set of discourse (the historical) and what was framed as 'stories/drama' in another set of discourse (the fictional) are in this model merged: there are facts in these stories just as there is drama in the history, both subject to critique and to empathetic teaching and learning.

3. And finally, to achieve interdisciplinary integration, we need to start at the beginning - with the course organization and syllabus — to effect a seamless, holistic structure that facilitates interdisciplinary dialogues and exchanges. When teachers cease to engage in "cross talk" (p. 5), students will then have the opportunity to get used to not expecting "a straight history course" or a "survey of literature" course, but to learn more integratively and collaboratively. As the authors themselves acknowledged towards the end of the book, the worry about losing objectivity in teaching a subject like the Shoah was in the end overshadowed by the positive "benefits of 'whole response" (p. 105) derived from integrating the affective with the cognitive.

Far from being "two courses pretending to be one" (p. 5), Tinberg and Weisberger's seminar succeeds to a large extent as a teaching project in interdisciplinary collaboration, an effort that in my view is worthy of emulation. The important contribution this work has made to SoTL lies in its explicit documentation of a difficult journey in teaching and learning, and in its demonstration of the possibilities of teaching and learning an equally difficult subject across two disciplines. In their own words, what they have gained for themselves is "less of mastery of the subject and more of a readiness to observe, to reflect on, and to write about the teaching of that subject" (p. 103). This, to me, is the triumph of this work: the teachers and students accepted a challenge in pedagogy to unlearn and relearn what everyone has taken for granted in viewing, teaching, and learning a subject from one perspective; walked in another person's (disciplinary) shoes to develop empathy for another point of view; and emerged with an enriched student's - and I hasten to add - and teacher's understanding of a traumatic catastrophic event in human history. Not only did the students learn, the teachers taught and no longer avoided confronting the Holocaust, and because they made that journey public, the SoTL community benefits from this active reflection on the collaborative road taken in that one classroom.

To say that I have enjoyed and learned a great deal from this book about the Shoah and about teaching is an understatement. I am grateful for having read it. I have been reminded of and have been given the opportunity to learn anew many important lessons in pedagogy, the most important being the integration of perspectives in full awareness of the challenges, and the promise, of such an endeavour. The authors may have begun this journey of symbiosis "for which [they] possessed no map" (p. 4), but they have now provided all of us with a map, no matter how imperfect, to embark on our own collaborative 
efforts in teaching. This is a book that I will unhesitatingly recommend to all teachers interested in pushing disciplinary boundaries and enhancing students' learning perspective through integrating multiple viewpoints. This is a journey worth taking.

Chng Huang Hoon is Associate Provost (Undergraduate Education) and an Associate Professor in the Department of English Language and Literature, National University of Singapore.

\section{NOTES}

1. Tinberg and Weisberger, 2014, p. 27.

\section{REFERENCES}

Chng, H. H. (2014). On "empathy's end": Teaching and learning as a journey in transformation. [Review of the book Teaching, learning, and the Holocaust: An integrative approach, by H. Tinberg \& R. Weisberger]. Asian Journal of the Scholarship of Teaching and Learning, 4(2), 130-136. Messer-Davidow, Ellen, David R. Shumway, and David J. Sylvan (1993, eds.), Knowledges: Historical and Classical Studies in Disciplinarity, Charlottesville: UP of Virginia.

Shulman, Lee S (1999), "Taking Learning Seriously", Change, July/August 1999, Volume 31, Number 4, pp. 10-17. Retrieved from http://www.carnegiefoundation.org/elibrary/taking -learning-seriously.

Tinberg, Howard, \& Weisberger, Ronald. (2014). Teaching, Learning, and the Holocaust: An Integrative Approach. Bloomington: Indiana University Press. 